\title{
MINIREVIEW \\ The yins and yangs of ceramide
}

\author{
KAMAL SHARMA, YUFANG SHI ${ }^{1}$ \\ Department of Immunology, Jerome H. Holland Laboratory, \\ American Red Cross, 15601 Crabbs Branch Way, Rockville, \\ MD 20855
}

\begin{abstract}
Since their discovery over 100 years ago, sphingolipids have caught the eyes and the imagination of scientists. Modern science has made many new insights on the cell biology and day-to-day functions of many integral sphingolipids, especially those of ceramide. Ceramide is recognized as a vital second messenger in the signal transduction process mediated by receptors of many cytokines and growth factors. A great part of our current understanding of ceramide has been achieved from apoptosis-related studies, however recent data in the fields of immunology, endocrinology and neurobiology, also suggest a fundamental involvement of ceramide in the onset of diseases. Therefore, understanding the biology of ceramide could be a key to unraveling many biological mechanisms and provide information for the treatment of some common diseases.
\end{abstract}

Key words: Ceramide, sphingomyelinase, signal, transduction.

\section{INTRODUCTION}

Common to members of the sphingolipid family is the "sphingosin" backbone,a

1. Please address correspondence to: Dr. Yufang Shi Department of Immunology Jerome H. HollanSd Laboratory American Red Cross 15601 Crabbs Branch Way, Rockville, MD 20855 USA. Tel: 301517 0392; Fax: 3015170344 E-mail: shiy@usa.redcross.org

ABBREVIATIONS: aSMase, acidic sphingomyelinase; nSMase, neutral sphingomyelinase; SMase, sphingomylinase; SM, sphingomyelin; SAPK/JNK, stress activated protein kinase/jun kinase; PDGF, platelet derived growth factor; LDL, low density lipoprotein; TNF/NGF, tumor necrosis factor/nerve growth factor; IFN- $\gamma$, interferon gamma; SLE, systemic lupus erythematosus; RA, rheumatoid arthritis; MAPK, mitogen activated protein kinase; NP, Niemann-Pick. 
The yins and yangs of ceramide

term coined by J. L. W. Thudichum in 1884 for its enigmatic ("Sphinx-like") properties[1]. Although still an elusive class of lipids, studies on the involvement of sphingolipids in signaling pathways that mediate cell growth, differentiation, cell death and multiple cell functions have been quickly expanding our comprehension of these compounds. In addition to many newly discovered roles of ceramide as an intracellular second messenger for the receptors of tumor necrosis factor-alpha (TNF- $\alpha$ ), IL-1- $\beta$, and other cytokines, sphingosine, sphingosine-1-phosphate, and other sphingolipid metabolites have recently been demonstrated to modulate cell proliferation and cellular calcium homeostasis [2, 3] Enzymatic degradation of sphingolipids like sphingomyelin (N-acylsphongosin-1phosphorylcholine; SM) is one of the major mechanisms for the generation of smaller lipid messengers. An important constituent of SM breakdown is ceramide, a second messenger generated in a plethora of signaling cascades[3]. Deregulation in intracellular ceramide levels is believed to be involved in many diseases such as diabetes, AIDS, neurodegenerative disorders, and autoimmunity[4]. It is noteworthy that although excessive amounts of ceramide is often toxic and results in apoptosis of many cell types[5], a basal level of this messenger is required for cell proliferation and differentiation. Reductions in steady-state ceramide has been shown to lead to growth arrest and an undifferentiated cellular phenotype[1], [6]. Therefore, a delicate balance in ceramide levels is needed for maintenance of proper cell fqunction.

\section{SM metabolism and generation of ceramide}

Cytoplasmic increases in ceramide can occur in two ways. De novo synthesis of ceramide is achieved through the condensation of serine and palmitoyl-CoA to form 3-oxosphinganine[1],[7]. 3-oxosphinganine is subsequently reduced to dihydrosphingosine, then acylated by ceramide synthase to yield dihydroceramide and oxidized to yield ceramide by the introduction of a trans-4, 5 double bond by dihydroceramide reductase[8]. This pathway can be stimulated by DNA-damaging substances such as daunorubicin or radiation and requires several hours for the generation of detectable ceramide[3],[7],[9]. Ceramide may also be produced via the action of several distinct enzymes involved in the cleavage of SM, namely acidic (a) and neutral (n) sphingomyelienases (aSMase and nSMase, respectively), which have been characterized based on their $\mathrm{pH}$-optima and biological effects[10]. Absence of aSMase ( $\mathrm{pH}$ optimum 4.5-5.0), originally described as a lysosomal enzyme defective in patients with Neimann-Pick (NP) syndrome[11] and more recently in aSMasedeficient mice[12], results in the inability to signal apoptosis. Acid SMase in both humans and mice have been cloned and determined to be the product of a conserved gene[13]. The aSMase protein is generated as a $75 \mathrm{kDa}$ precursor which is processed to a final species of 70 and/or $57 \mathrm{kDa}[3],[8],[14],[15]$. An acidic environment enhances the catalytic activity of aSMase, but is not absolutely required for its function. Besides the endosomal aSMase, many stimuli also rapidly activate a 
plasmamembrane-associated nSMase (pH optimum 7.4)[16]. Knockout studies of aSMase have revealed that nSMase activity is still retained in these mice, indicating that aSMase and nSMase are the products of separate genes and function individually[3],[8],[14],[16]. Ceramide generated by nSMase activities leads to the upregulation of proline-directed serine/threonine protein kinases and phospholipases and has been implicated to be important in cell proliferation and inflammation[17]. It should be noted that there exist two forms of nSMase, one is cytosolic, $\mathrm{Mg}^{2+}$ independent and the other is membrane-bound, $\mathrm{Mg}^{2+}$-dependent[17],[18]. Generation of ceramide through the activation of SMases can be induced by apoptotic stimuli (i.e. negative signals) leading to the induction of well-known cell death mediators and initiators, such as BAD/BAX, Apaf1, cytochrome C, and the activation of the SAPK/JNK pathway[8],[16]. Cytochrome $\mathrm{C}$ and Apaf1 will liberate inactive caspases from a dormant state, unleashing their fury and unrelenting destruction of most if not all cellular constituents. The exact nature of SAPK/JNK involvement in ceramideinduced cell death is not entirely understood, however it is believed that the stress pathway enables the expression of cytotoxic death ligands like FasL[5],[6],[8],[16]. SMases can also be activated by positive signals elicited by PDGF, CD28 and oxidized LDL resulting in the transcription of growth-related genes through the activation of the MAPK pathway and upregulation of a plethora of essential cellular functions like cell growth, differentiation and repair[5],[6],[7]. (Fig 1) Some well recognized reagents which initiate the breakdown of SM throught the activation of aSMase include negative signals, such as members of the TNF/NGF superfamily of receptors/ligands (TNF- $\beta$, Fas [CD95] and NGF), $\gamma$-irradiation, cytokines (IFN- $\gamma$ and IL-1), stress (UV, heat shock, free radicals) and chemotherapeutic drugs[16],[20]. Alternatively, there are many positive signals like PDGF, CD28 and oxidized LDL which can also lead to increases in stead-state ceramide concentrations through the activction of nSMase[1],[6],[9]. The negative signaling cascade leading to the liberation of ceramide from SM appears to mediate apoptosis by the activation of certain kinases[20]. These negative signals will activate aSMase causing ceramide liberation. In the negative signaling pathway ceramide behaves as a second messenger in the initiation of apoptotic cell death in a variety of pathophysiologic settings [21]. Application of exogenous ceramide alone, using cell permeable ceramide analogs such as $\mathrm{C}_{2}, \mathrm{C}_{6}$ and $\mathrm{C}_{8}$ isoforms, is sufficient to initiate apoptosis[14]. By contrast, the use of fumonisin B1, a specific ceramide synthase inhibitor provides a marked protection against chemical hypoxia-induced DNA strand breaks, DNA fragmentation, and cell death[22]. Interestingly, activation of the TNF-receptor can lead to induction of both nSMase and aSMase through different cytoplasmic domains of the $55 \mathrm{kDa}$ TNF-receptor[16]. There seem to be selective, uncoupled pathways of TNF signaling with no apparent cross-talk being detected between nSMase and aSMase pathways, indicating that ceramide action depends on the topology of its production. 
The yins and yangs of ceramide

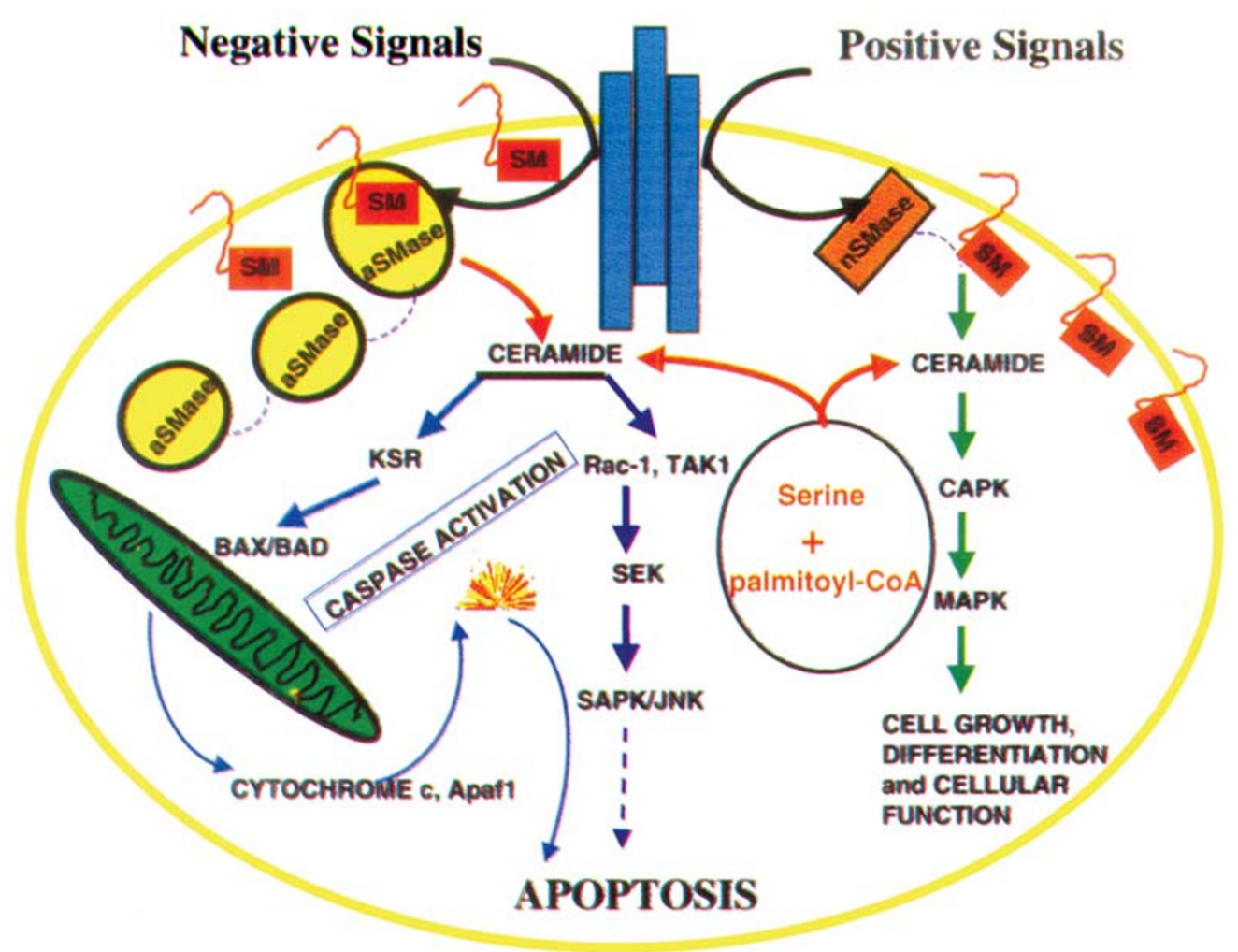

Fig 1. Hydrolysis of sphingomyelin (SM) through activation of endosomal acidic (a) and neutral (n) sphingomyleinase (SMase). Negative signals such as chemotherapeutic drugs, members of the TNF/NGF family and stresses (physical, oxidative, chemical) will generate ceramide via SM cleavage through upregulation of nSMase. Ceramide in this pathway will either induce the inhibitory kinase suppressor of ras (KSR), which induces apoptosis through $\mathrm{BAD}$ and $\mathrm{BAX}$. BAD/BAX will effect mitochondrial transmembrane potential, resulting in cytochrome $\mathrm{C}$ and Apaf-1 release and the activation of caspases, which carry out apoptosis. Althernatively, ceramide can upregulate transforming growth factor-b-activated kinase (TAK1) or the small molecular weight GTP-binding protein Rac-1, resulting in induction of the stress-activated protein kinase, jun kinase (SAPK/JNK) pathway. On the other hand, positive signals such as oxidized low density lipoproteins (LDL), CD28 and platelet derived growth factor (PDGF) can cleave SM through activation of the membrane bound nSMase. Ceramide generated by nSMase will result in turning on the mitogen-activated protein kinase (MAPK) pathway via the action of ceramide-activated protein kinase (CAPK). This cascade will induce cell growth, differentiation and upregulation of vital cellular functions.

\section{Disease and ceramide involvement}

The biological role of ceramide is complex, as well as multi-faceted. As mentioned above, 
ceramide is a critical component in the signaling pathway of many receptor-ligand interactions including that of Fas/Fasl, TNFR/TNF and PDGF[5],[6],[8],[16]. In the PDGF system, the inability to generate ceramide leads to growth arrest and loss of cellular differentiation, while in the systems of Fas/FasL and TNFR/TNF, ceramide is a key effector for the induction of apoptosis. Loss in the balance of ceramide production, either through SM hydrolysis or de novo synthesis, can have devastating consequences ranging from the increased rates of apoptosis (when high) or loss in tissue growth and function (when low). The evolution of many immunological diseases centers around an imbalance in T-cells. $\mathrm{CD} 4^{+} \mathrm{T}$ helper $(\mathrm{Th})$ cells are fundamental in the regulation of cell mediated immune response and antibody production by B-cells. Based on the analysis of cytokines produced by long term cultured T cell clones, CD4 ${ }^{+} \mathrm{T}$ cells have been divided into Th1 and Th2[23]. Th1 clones, through their production of IL-2, IFN- $\gamma$, and TNF a, are responsible to induce cellular immunity; whereas Th2 cells secreting IL-4, IL-5, IL-10, and IL-13 are important in helping B cells develop into antibody-producing cells, and mediate anti-inflammatory response[23],[24]. The Th1/Th2 phenotypic distinction can be related to in vivo immune responses in certain infectious and autoimmune diseases in mice[25] and humans, demonstrating the pathophysiological significance of these two types of immune responses[26],[27]. Passive regulation of Th1/Th2 responses with cytokines, soluble cytokine receptors and their specific neutralizing antibodies could dramatically influence the outcome of infections and some autoimmune reactions [28-30]. Two prototypical autoimmune diseases, rheumatoid arthritis (RA) and systemic lupus erythematosus (SLE) arise from 2 different immune responses that generate mutually exclusive signals in response to different inflammatory triggers[26], [27]. RA is mediated by Th1 T-cells, while SLE Th2 and interestingly ceramide production in these two diseases also show distinct patterns[31],[32]. The shift in Th1 to Th2 cytokine production pattern is a common feature of SLE patients and is believed to be the critical factor leading to the onset of the disease[33]. In addition, SLE patients have high Th2 T cell activity possibly caused by increases in ceramide. Exogenous ceramide induces a heightened rate of proliferation of $\mathrm{T}$ cells[34], and the use of fumonisin B1 can markedly suppress ceramide-induced T cell proliferation[35], suggesting that the ceramide pathway may be involved in stimulating SLE Th2 cells.

Ceramide is believed to be a critical factor in the pathogenesis of SLE. SLE patients possess high levels of ceramide[32],[36] and moreover, in vitro studies using sphingosine and synthetic cell-permeable analogs of ceramide showed augmented mRNA expression of interleukin-4 (IL-4) and enhanced expression of the IL-4 receptor in Th2 T-cells[37]. It is thus likely that a ceramide-initiated shift in cytokine production favoring Th2 could be promoting SLE disease onset.

SLE is a consequence of an overproduction of autoantibodies against cellular and nuclear components released from apoptotic cells[33], [38]. Unlike in healthy 
The yins and yangs of ceramide

individuals, significant number of apoptotic cells circulate in SLE patients[38]. It has also been shown that phagocytes of SLE patients are defective in removing apoptotic cells[39], it is possible that a sudden increase in apoptotic cells in the absence of efficient phagocytosis could trigger SLE. In addition, the deposition of immune complexes in various organs and tissues also induces apoptosis, which contributes to the overall pathogenesis of SLE. The loss of macrophage phagocytic activity in SLE has been proposed to be due to increases in ceramide levels[40]. Attenuation of ceramide production has been shown to reverse this inhibition and lead to increases in macrophage mobility and activity,[40], [41a, b]. Moreover, it should be noted that macrophages can themselves exert antigen-presenting cell activity to strongly skew primary responses to cellular immunity, and suppress Th2dependent humoral response[42]. Furthermore, there is a selective immunogobulin deficiency associated with Niemann-Pick disease (no aSMase), indicating a role for ceramide in promoting Th2 type antibody production[43]. Thus, inhibition of macrophage function by ceramide would serve to switch the T-cell balance from Th1 to Th2. These facts demonstrate a pivotal role for ceramide in SLE disease status.

Although ceramide deregulation has been principally studied in the immune system, it has also been implicated in the onset of disorders in the endocrine, vascular and central nervous systems $[1,16,20]$. Ceramide mediates the effects of cytokines on endocrine function, where ceramide may predispose to diabetes by affecting pancreatic $\beta$-cell function. Zucker fatty diabetic rats manifest high levels of ceramide and apoptosis[44]. Administration of fumonisin B1 blocked both ceramide generation and apoptosis of $\beta$-cells[44]. Moreover, increase in ceramide by TNFa inhibited protein phosphatase- 1 activation, resulting in a loss of glucose uptake and storage, and contributing to the overall pathology of diabetes[45]. In the vascular system, increases in ceramide is a contributing factor to renal failure following ischaemia/ reperfusion which is associated with high levels of apoptosis, whereas in coronary arteries ceramide increase stimulated by oxidized LDL results in the proliferation of vascular smooth muscle cells potentiating atherosclerosis,[46,47]. By contrast, the absence of ceramide in specialized areas of the brain like the nigro-striatal neurons is believed to result in the death of these neurons, leading to Parkinson's disease[50,51]. $\mathrm{C}_{2}$-ceramide has been shown to protect hippocampal neurons from death induced by amyloid $\beta$-peptide, suggesting that a basal level of ceramide is required for the delay of Alzheimer's disease[52],[53]. Increases in ceramide are notably beneficial for delaying the onset of calssical ncurodegenerative diseases, however these same increases can be employed in limiting uncontrolled cell growth. High amounts of ceramide usually lead to apoptosis and this destructive property can be used as a powerful weapon for killing tumor cells. Studies in aSMase knockout mice and NP patients have revealed the absence of apoptosis following massive exposure to chemoand radiation-therapy[12]. Furthermore, restoration of aSMase activity in NP patients with retroviral transfer of human aSMase cDNA was able to reverse such 
effects[12]. Numerous reperts have revealed that raising intracellular ceramide levels via activation of SMases by chemotherapeutic agents resulte in rapid death of cancer cells[5],[54]. Moreover, it is believed that the generation of ceramide by chemo/radiation-therapy provides a novel target for the elimination of tumors and opens a new avenue of treatment in those patients who have developed multi-drug resistant cancer[55]. Thus, ceramide has great potential for eliminating aberrant cells in circumstances when they are not desired. Given the pleiotropic functions of ceramide in a plethora of signaling systems and its involvement in the etiology of many diseases, it is possible that new approaches to treat diseases could be by modulating ceramide levels, either through reduction in de novo ceramide synthesis or ceramide release through blockade of $\mathrm{n}$ - and aSMase activity. Inhibition of intracellular ceramide would potentially be beneficial to patients with SLE, atherosclerosis, and neurodegenerative disorders.

\section{Conclusion}

The SM pathway is clearly a vital component in cellular signaling, of which ceramide plays a central role. Alterations in ceramide production, either the inability to increase ceramide levels or loss in the suppression of ceramide generation, is paramount and often contributes to disease onset. High concentrations of ceramide can result in an inordinate degree of cell death causing tissue damage and organ failure, as observed in SLE and diabetes. In contrast, a continuous basal level of ceramide is essential in staving off many neurodegenerative diseases like Parkinson's and Alzheimer's. Moreover, ceramide production is a necessary evil for the death of tumorigenic cells and is a key response in chemo- and radiation-therapy of cancer patients. Even though much has been worked out on the signaling, consequences and ramifications of changes in ceramide levels, a great deal of work still needs to be carried out. Further understanding of changes in ceramide's actions is needed to fully appreciate and utilize this important signaling molecule in the prevention of many diseases and in the contra-regulation of others.

\section{ACKNOWLEDGEMENT}

This work was supported by National Institutes of Health Research Grants AI43384 and CA53609 to Y.F.S.

\section{REFERENCES}

[1] Merrill AH Jr, Schmelz EM, Dillehay DL, Spiegel S, Shayman JA, Schroeder JJ, Riley RT, Voss KA, Wang E. Sphingolipids-the enigmatic lipid class: biochemistry, physiology, and pathophysiology Toxicol Appl Pharmacol 1997; 142(1):208-25.

[2] Karlsson KA. On the character and functions of sphingolipids. Acta Biochim Pol 1998; 45(2):42938. 
The yins and yangs of ceramide

[3] Perry DK, Hannun YA. The role of ceramide in cell signaling. Biochim Biophys Acta 1998; 1436(1-2):233-43.

[4] Sandhoff K, Kolter T, Van Echten-Deckert G. Sphingolipid metabolism. Sphingoid analogs, sphingolipid activator proteins, and the pathology of the cell. Ann N zzY Acad Sci 1998 Jun 19; 845:139-51.

[5] Jarvis WD, Grant S. The role of ceramide in the cellular response to cytotoxic agents. Curr Opin Oncol 1998; 10(6):552-9.

[6] Spiegel S, Merrill AH. Jr Sphingolipid metabolism and cell growth regulation. FASEB J 1996; 10(12):1388-97.

[7] Spiegel S, Foster D, Kolesnick R. Signal transduction through lipid second messengers. Curr Opin Cell Biol 1996; 8(2):159-67.

[8] Bose R, Verheij M, Haimovitz-Friedman A, Scotto K, Fuks Z, Kolesnick R. Ceramide synthase mediates daunorubicin-induced apoptosis: an alternative mechanism for generating death signals. Cell 1995; 82(3):405-14.

[9] Hofmann K, Dixit VM. Ceramide in apoptosis-does it really matter? Trends Biochem Sci 1998; 23(10):374-7.

[10] Jaffrezou JP, Levade T, Bettaieb A, Andrieu N, Bezombes C, Maestre N, Vermeersch S, Rousse A, Laurent G. Daunorubicin-induced apoptosis: triggering of ceramide generation through sphingomyelin hydrolysis. EMBO J 1996; 15(10):2417-24.

[11] Schneider PB, Kennedy EP. Sphingomyelinase in normal human spleens and in spleens from subjects with Niemann-Pick disease. J Lipid Res 1967; 8(3):202-9.

[12] Santana P, Pena LA, Haimovitz-Friedman A, Martin S, Green D, McLoughlin M, CordonCardo C, Schuchman EH, Fuks Z, Kolesnick R. Acid sphingomyelinase-deficient human lymphoblasts and mice are defective in radiation-induced apoptosis. Cell 1996; 86(2):189-99.

[13] Schuchman EH, Suchi M, Takahashi T, Sandhoff K, Desnick RJ. Human acid sphingomyelinase. Isolation, nucleotide sequence and expression of the full-length and alternatively spliced cDNAs. J Biol Chem 1991; 266(13):8531-9.

[14] Irie F, Hirabayashi Y. Application of exogenous ceramide to cultured rat spinal motoneurons promotes survival or death by regulation of apoptosis depending on its concentrations. J Neurosci Res 1998; 15; 54(4):475-85.

[15] Hurwitz R, Ferlinz K, Vielhaber G, Moczall H, Sandhoff K. Processing of human acid sphingomyelinase in normal and I-cell fibroblasts. Biol Chem 1994; 269(7):5440-5.

[16] Kolesnick RN, Kronke M. Regulation of ceramide production and apoptosis Ann. Rev Physiol 1998; 60:643-5.

[17] Okazaki T, Bielawska A, Domae N, Bell RM, Hannun YA. Characteristics and partial purifica tion of a novel cytosolic, magnesium-independent, neutral sphingomyelinase activated in the early signal transduction of 1 alpha, 25-dihydroxyvitamin D3-induced HL-60 cell differentiation. J Biol Chem 1994; 269(6):4070-7.

[18] Spence MW, Wakkary J, Clarke JTR, Cooke HW. Localization of neutral magnesium-stimulated sphingomyelinase in plasma membrane of cultured neuroblastoma cells. Biochim Biophys Acta 1982; 719(1):162-4.

[19] Otterbach B, Stoffel W. Acid sphingomyelinase-deficient mice mimic the neurovisceral form of human lysosomal storage disease (Niemann-Pick disease). Cell 1995; 81(7):1053-61.

[20] Mathias S, Pena LA, Kolesnick RN. Signal Transduction of stress via ceramide. Biochem J 1998 335: 465-80.

[21] Adam-Klages S, Schwandner R, Adam D, Kreder D, Bernardo K, Kronke M. Distinct adapter proteins mediate acid versus neutral sphingomyelinase activation through the p55 receptor for tumor necrosis factor. J Leukoc Biol 1998; 63(6):678-82.

[22] Ueda N, Kaushal GP, Hong X, Shah SV. Role of enhanced ceramide generation in DNA damage and cell death in chemical hypoxic injury to LLC-PK1 cells. Kidney Int 1998; 54(2):399-406.

[23] Mosmann TR, Cherwinski H, Bond MW, Giedlin MA, Coffman RL. Two types of murine helper T cell 


\section{Sharma K and YF Shi}

clone. I. Definition according to profiles of lymphokine activities and secreted proteins. Immunol 1986; 136(7):2348-57.

[24] Mosmann TR, Sad S. The expanding universe of T-cell subsets: Th1, Th2 and more. Immunol Today $1996 ; 17(3): 138-46$.

[25] Liu MF, Ning Q, Pope M, Mosmann T, Leibowitz J, Ding JW, Fung LS, Rotstein O, Gorczynski R, Levy GA. Resistance of naive mice to murine hepatitis virus strain 3 requires development of a Th1, but not a Th2, response, whereas pre-existing antibody partially protects against primary infection. Adv Exp Med Biol 1998; 440:415-23 .

[26] Kasakura S. A role for T-helper type 1 and type 2 cytokines in the pathogenesis of various human diseases. Rinsho Byori 1998 46(9):915-21.

[27] Lucey DR, Clerici M, Shearer GM. Type 1 and type 2 cytokine dysregulation in human infectious, neoplastic, and inflammatory diseases. Clin Microbiol Rev 1996; 9(4):532-62.

[28] Gessner A, Rollinghoff M. Soluble IL-4 receptor, potential for therapeutic and prophylactic intervention. M Behring Inst Mitt 1994; 95:35-41.

[29] Fishman MA, Perelson AS. Th1/Th2 cross regulation. J Theor Biol 1994; 170(1):25-56.

[30] Wang Y, Ardestani SK, Liang B, Beckham C, Watson RR. Anti-IL-4 monoclonal antibody and IFNgamma administration retards development of immune dysfunction and cytokine dysregulation during murine AIDS. Immunology 1994; 83(3):384-9.

[31] Mizushima N, Kohsaka H, Miyasaka N. Ceramide, a mediator of interleukin 1, tumor necrosis factor alpha, as well as Fas receptor signaling, induces apoptosis of rheumatoid arthritis synovial cells. Ann Rheum Dis 1998; 57(8):495-9.

[32] Sakata K, Sakata A, Vela-Roch N, Espinosa R, Escalante A, Kong L, Nakabayashi T, Cheng J, Talal N, Dang H. Fas (CD95)-transduced signal preferentially stimulates lupus peripheral T lymphocytes. Eur J Immunol 1998; 28(9):2648-60.

[33] Mason LJ, Isenberg DA. Immunopathogenesis of SLE. Baillieres Clin Rheumatol 1998; 12(3):385403.

[34] Jolly CA, Laurenz JC, McMurray DN, Chapkin RS. Diacylglycerol and ceramide kinetics in primary cultures of activated T-lymphocytes. Immunol Lett 1996; 49(1-2):43-8.

[35] Martinova EA. Influence of sphingolipids on T lymphocyte activation. Biochemistry (Mosc) 1998; 63 (1):102-10.

[36] Koerner TA, Weinfeld HM, Bullard LS, Williams LC. Antibodies against platelet glycosphingolipids: detection in serum by quantitative HPTLC-autoradiography and association with autoimmune and alloimmune processes. Blood 1989; 74(1):274-84.

[37] Tokura Y, Wakita H, Yagi H, Nishimura K, Furukawa F, Takigawa M. Th2 suppressor cells are more susceptible to sphingosine than Th1 cells in murine contact photosensitivity. Invest Dermatol 1996; 107(1):34-40.

[38] Elkon KB. Apoptosis in SLE-too little or too much? Clin Exp Rheumatol 1994; 12(5):553-9.

[39] Herrmann M, Voll RE, Zoller OM, Hagenhofer M, Ponner BB, Kalden JR. 1998 Impaired phagocy tosis of apoptotic cell material by monocyte-derived macrophages from patients with systemic lupus erythematosus. Arthritis Rheum. 1998; 41(7):1241-50.

[40] Lutjohann J, Spiess AN, Gercken G. Agonist-stimulated alveolar macrophages: apoptosis and phospholipid signaling. Toxicol Lett 1998; 96:59-67.

[41a] Zhu JS, Halpern GM, Jones K. The scientific rediscovery of an ancient Chinese herbal medicine: Cordyceps sinensis: part I. J. Altern Complement Med 1998 Fall; 4(3):289-303.

[41b] Zhu JS, Halpern GM, Jones K. The scientific rediscovery of a precious ancient Chinese herbal regimen: Cordyceps sinensis: part II. J Altern Complement Med 1998; 4(4):429-57.

[42] Desmedt M, Rottiers P, Dooms H, Fiers W, Grooten J. Macrophages induce cellular immunity by activating Th1 cell responses and suppressing Th2 cell responses. J Immunol 1998; 160(11):5300-8.

[44] Kikindjanin V, Kleut-Jelic R, Velisavljev M, Milakov J, Popic-Paljic F. Selective IgA deficiency associ 
The yins and yangs of ceramide

ated with Niemann-Pick disease. Allerg Immunol (Leipz) 1984; 30(1):46-8.

[45] Shimabukuro M, Zhou YT, Levi M, Unger RH. Fatty acid-induced beta cell apoptosis: a link between obesity and diabetes. Proc Natl Acad Sci USA 1998; 95(5):2498-502.

[46] Begum N, Ragolia L, Srinivasan M. Effect of tumor necrosis factor-alpha on insulin-stimulated mitogen-activated protein kinase cascade in cultured rat skeletal muscle cells. Eur J Biochem 1996; 238(1):214-20.

[47] Schissel SL, Tweedie-Hardman J, Rapp JH, Graham G, Williams KJ, Tabas I. Rabbit aorta and human atherosclerotic lesions hydrolyze the sphingomyelin of retained low-density lipoprotein. Proposed role for arterial-wall sphingomyelinase in subendothelial retention and aggregation of atherogenic lipoproteins. Clin Invest 1996; 98(6):1455-64.

[48] Auge N, Escargueil-Blanc I, Lajoie-Mazenc I, Suc I, Andrieu-Abadie N, Pieraggi MT, Chatelut M, Thiers JC, Jaffrezou JP, Laurent G, Levade T, Negre-Salvayre A. Potential role for ceramide in mitogen-activated protein kinase activation and proliferation of vascular smooth muscle cells induced by oxidized low density lipoprotein. R J Biol Chem 1998; 273(21):12893-900.

[49] Singh I, Pahan K, Khan M, Singh AK. Cytokine-mediated induction of ceramide production is redoxsensitive. Implications to proinflammatory cytokine-mediated apoptosis in demyelinating diseases J Biol Chem 1998; 273(32):20354-62.

[50] Larocca JN, Farooq M, Norton WT. Induction of oligodendrocyte apoptosis by C2-ceramide. Neurochem Res 1997; 22(4):529-34.

[51] France-Lanord V, Brugg B, Michel PP, Agid Y, Ruberg M. Mitochondrial free radical signal in ceramide-dependent apoptosis: a putative mechanism for neuronal death in Parkinson's disease. J Neurochem 1997; 69(4):1612-21.

[52] Hunot S, Brugg B, Ricard D, Michel PP, Muriel MP, Ruberg M, Faucheux BA, Agid Y, Hirsch EC. Nuclear translocation of NF-kappaB is increased in dopaminergic neurons of patients with parkinson disease. Proc Natl Acad Sci USA 1997; 94(14):7531-6.

[53] Mattson MP, Barger SW, Furukawa K, Bruce AJ, Wyss-Coray T, Mark RJ, Mucke L. Cellular signaling roles of TGF beta, TNF alpha and beta APP in brain injury responses and Alzheimer's disease. Brain Res Brain Res Rev 1997; 23(1-2):47-61.

[54] Goodman Y, Mattson MP. Ceramide protects hippocampal neurons against excitotoxic and oxidative insults, and amyloid beta-peptide toxicity. Neurochem 1996; 66(2):869-72.

[55] Laethem RM, Hunnun YA, Jayadev S, Sexton CJ, Strum JC, Sundseth R, Smith GK. Increases in neutral, $\mathrm{Mg}^{2+}$-dependent and acidic, $\mathrm{Mg}^{2+}$-independent sphingomyelinase activities precede commitment to apoptosis and are not a consequence of caspase 3-like activity in Molt-4 cells in response to thymidylate synthase inhibition by GW1843. Blood 1998; 91(11):4350-60.

[56] Cabot MC, Giuliano AE, Han TY, Liu YY. SDZ PSC 833, the cyclosporine A analogue and multidrug resistance modulator, activates ceramide synthesis and incerases vinblastine sensitivity in drugsensitive and drug-resistant cancer cells. Cancer Res 1999; 59(4):880-5. 